\title{
Precipitation instruments at Rothera Station, Antarctic Peninsula: a comparative study
}

\author{
Malcolm S.Y. Tang $\oplus^{a}$, Sheeba Nettukandy Chenolia,b,c, Steve Colwell ${ }^{d}$, Rosey Grant ${ }^{d}$, Mairi Simms ${ }^{d}$, \\ John Law ${ }^{\mathrm{d}, \mathrm{e}}$ \& Azizan Abu Samah ${ }^{\mathrm{a}, \mathrm{b}, \mathrm{c}}$
}

aNational Antarctic Research Centre, Institute of Graduate Studies, University of Malaya, Kuala Lumpur, Malaysia; bepartment of Geography, Faculty of Arts and Social Sciences, University of Malaya, Kuala Lumpur, Malaysia; Institute of Ocean and Earth Sciences, University of Malaya, Kuala Lumpur, Malaysia; ${ }^{B}$ British Antarctic Survey, Cambridge, UK; eMetService, Wellington, New Zealand

\begin{abstract}
Direct measurement of precipitation in the Antarctic using ground-based instruments is important to validate the results from climate models, reanalyses and satellite observations. Quantifying precipitation in Antarctica faces many unique challenges such as wind and other technical difficulties due to the harsh environment. This study compares a variety of precipitation measurements in Antarctica, including satellite data and reanalysis fields atRothera Station, Antarctica Peninsula. The tipping bucket gauges (TBGs) were less sensitive than laserbased sensors (LBSs). The most sensitive LBS (Visibility and Present Weather Sensor, VPF-730) registered 276 precipitation days, while the most sensitive TBG (Universal Precipitation Gauge, UPG-1000) detected 152 precipitation days. Case studies of the precipitation and seasonal accumulation results show the VPF-730 to be the most reliable precipitation sensor of the evaluated instruments. The precipitation amounts given by the reanalyses were positively correlated with wind speed. The precipitation from the Japanese 55-year Reanalysis was most affected by wind speed. Case studies also show that during low wind periods, precipitation measurements from the instruments were very close to the precipitation measurement given by the Global Precipitation Climatology Project (GPCP) 1-degreedaily (1DD) data. During strong wind events, the GPCP 1DD did not fully capture the effect of wind, accounting for the relatively small precipitation amount. The Laser Precipitation Monitor (LPM) and Campbell Scientific-700 (CS700H) experienced instrumental errors during the study, which caused the precipitation readings to become exceedingly high and low, respectively. Installing multiple LBSs in different locations (in close proximity) can help identify inconsistency in the readings.
\end{abstract}

\section{KEYWORDS}

Observation; Antarctica; reanalysis; GPCP 1DD; blowing snow

\section{ABBREVIATIONS}

CFSv2: Climate Forecast System version 2; $\mathrm{CS} 700 \mathrm{H}$ : Scientific Rain Gauge, by Campbell Scientific; ECMWF: European Centre for Medium-Range Weather Forecasts; ERA-Int: European Centre for Medium-range Weather Forecasts Interim reanalysis data set; GPCP: Global Precipitation

Climatology Project data set; JRA-55: Japan

Meteorological Agency 55year Reanalysis; LBS: laserbased sensor; LPM: Laser Precipitation Monitor, by Thies; NCEP: National Centre for Environmental

Prediction; PWS-100 Scientific Present Weather Sensor, by Campbell Scientific; TBG: tipping bucket gauge; UPG-1000: Universal Precipitation Gauge 1000, by Environmental Measurements Limited; VPF730: Visibility and Present Weather Sensor 730, by Biral

\section{Introduction}

Because precipitation is an important component of Antarctic surface mass balance dynamics, obtaining robust and reliable precipitation profiles of the Antarctic is one of the main objectives of climate study of the southern continent (Agosta et al. 2015). Limited accessibility, power constraints and the harsh climate limit precipitation profiles to manned research stations. Even then, the strong winds in Antarctica, which can sometimes travel up to $20 \mathrm{~ms}^{-1}$, resulting in blowing snow (Van Lipzig et al. 2004), have a profound effect on the accuracy and reliability of instrument-based precipitation measurements. Previous studies have shown that the relatively slow fall velocity of snow and the creation of flow distortions by precipitation gauges are two main causes for snow undercatch (Folland 1988). For a precipitation gauge with an open funnel, an updraft could form at the leading edge of the gauge, leading to an upward deflection of snow particles away from the gauge orifice (Kochendorfer et al. 2017). Flow distortion around the gauge will increase with increasing wind speed, deflecting more snow particles away from the gauge. Scientists also measure accumulation using stakes, ice or firn cores and acoustic depth gauges, as proxies for precipitation, but this measurement is not straightforward (Cohen \& Dean 2013). In view of the logistic difficulty in obtaining reliable precipitation measurements, researchers have resorted to using other means, 
like satellite observations (Bindschadler et al. 2005; Palerme et al. 2014), reanalysis data sets (Bromwich et al. 2011) and climate models (Fyfe et al. 2012; Palerme et al. 2017). Satellite and radar technologies are not subjected to the harsh environment of the Antarctic and can observe vast regions with increasing resolution. However, there are only two reliable satellite data sets available for the Antarctic: the GPCP and CloudSat (Huffman et al. 1997; Stephens et al. 2002). The accuracy of the GPCP 1-degree-daily (1DD) product has yet to be tested against in situ precipitation measurements in the Antarctic. CloudSat relies heavily on a satellite whose narrow orbital track allows it to cover only a limited surface and period (Palerme et al. 2014), so it cannot provide continuous and consistent daily measurements of precipitation. For the interior of the Antarctic, the CloudSat algorithm cannot detect small snow particles (Palerme et al. 2017). On the other hand, oceanographic and atmospheric models are very sensitive to their respective forcing data (Jones et al. 2016). Moreover, the resolution of currently available climate models (ranging from $1.5^{\circ}$ to $3.0^{\circ}$ ) prohibits a direct comparison of point precipitation, and allows only the long-term seasonality comparison of regional precipitation and its trend. In situ precipitation measurement can be used as a standard for validating precipitation observations from satellites and the long-term results obtained from climate models and reanalysis data sets. As suggested by Wang et al. (2016), previous comparisons of climate models with unreliable field observations may produce inaccurate and therefore unreliable reports (Wang et al. 2016).

The literature for direct precipitation measurement in Antarctica is sparse (Lachlan-Cope et al. 2001; Kirchgäßner 2011; Palerme et al. 2014) and often limited to only one type of precipitation sensor (LachlanCope et al. 2001; Bellot et al. 2011) or short study period (Lachlan-Cope et al. 2001). The difficulty of precipitation observation in the Antarctic is often repeated in Antarctic precipitation reports (Genthon et al. 2003; Bromwich et al. 2004; Miles et al. 2008). Wind is one of the main factors that affect precipitation measurement (Yang 1999; Van Lipzig et al. 2004; Cohen \& Dean 2013). Even in regions where precipitation falls as rain water, strong wind affects measurements by inducing undercatch and wetting losses (Benning \& Yang 2005). In the Antarctic, the effect of distribution of snow is a difficult process to study as it involves several other parameters, such as snow age, snow moisture, temperature, local topography and the size of the snow particles (Li \& Pomeroy 1997).

To address the technical challenges associated with precipitation measurement it is important to first compare and analyse the performance of precipitation measuring technology already in operation. It is not the intention of this work to examine the different technical aspects of precipitation instruments, but rather to help future researchers to select appropriate precipitation sensors. In this work, precipitation measurement obtained from five different types of precipitation sensors hosted at Rothera Research Station in the Antarctic Peninsula from March 2015 to February 2016 were analysed and compared with reanalyses data sets, namely ERA-Int, JRA-55, the NCEP's CFSv2 model, as well as the GPCP 1DD satellite product data set.

\section{Precipitation sensors used in antarctica}

There are two categories of instruments used in this study: TBGs and LBSs, also known as disdrometers. A TBG measures primarily the total amount of falling precipitation, while disdrometers have the ability to measure the nature of individual precipitation particles (Michaelides et al. 2009).

\section{Tipping bucket gauge}

\section{$\mathrm{CS} 700 \mathrm{H}$ scientific rain gauge}

At Rothera Station, a Campbell Scientific CS700H gauge, contributed by the National Antarctic Research Centre, University of Malaya, was installed during the summer of 2014/15 (Fig. 1a). The diameter of the orifice is $20.0 \mathrm{~cm}$, with a resolution of $0.254 \mathrm{~mm}$. The working principle of this gauge relies on gravity to pull the precipitation particles through the measuring funnel. In addition, this gauge is equipped with a heating feature that automatically turns on when the temperature of the funnel drops below $4^{\circ} \mathrm{C}$. The temperature of the gauge will then be maintained at between 4 and $10^{\circ} \mathrm{C}$. This allows the snow to melt and flow through the funnel into the tipping bucket below. At Rothera, the $\mathrm{CS} 700 \mathrm{H}$ was installed without a wind shield.

\section{UPG-1000 universal precipitation gauge}

The UPG-1000 has an almost similar design to the $\mathrm{CS} 700 \mathrm{H}$ mentioned above, except that the design of the funnel is much wider (up to $1000 \mathrm{~cm}^{2}$ ) and deeper, which functions to capture more snow particles and to minimize the effect of wind (Dutton et al. 2008). Its aerodynamic design also functions to deflect the wind and to reduce error. The UPG-1000 has a resolution of $0.1 \mathrm{~mm}$. Similar to the $\mathrm{CS} 700 \mathrm{H}$, this gauge utilizes a low voltage heating element to melt the snow that falls into the funnel to prevent blockage from the formation of ice. The heating element is controlled by a temperature sensor in the funnel, which turns on the heater when the ambient temperature approaches $0^{\circ} \mathrm{C}$. The gauge was installed with a wind shield to reduce the influence of wind (Fig. 1b). The shield - a so-called Alter screen - was developed by Environmental Measurements Limited, which also supplied the UPG-1000. The Alter screen has swinging leaves to prevent the accumulation of snow (Dutton et al. 2008). 

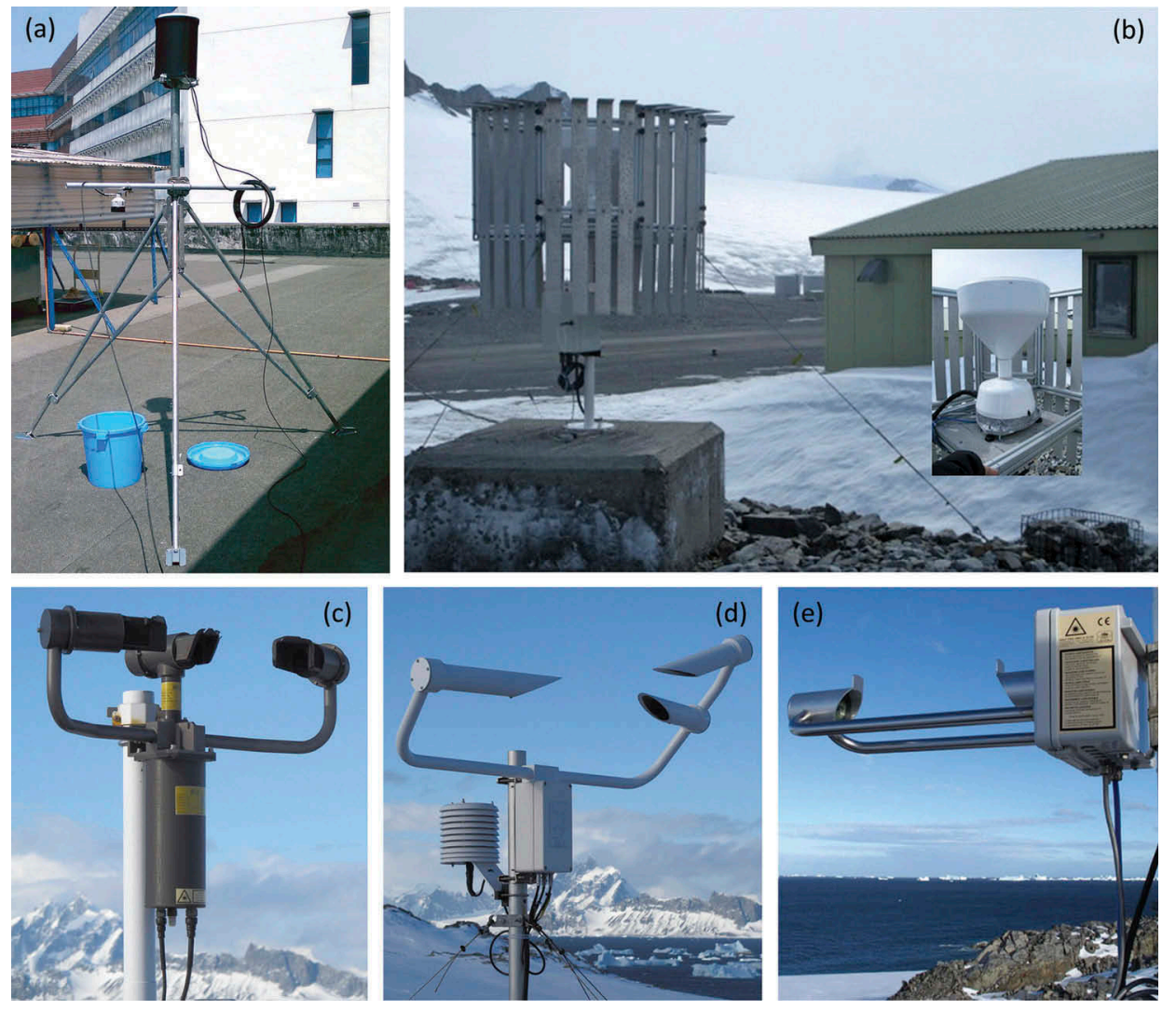

Figure 1. (a) The $\mathrm{CS700H}$, seen here with the SR50 snow depth sensor (on the left on the horizontal rod), undergoes a test at a site at the University of Malaya before deployed to Rothera. (b) The wind shield installed around the UPG-1000 (inset). (c) A VPF730 sensor. (d) PWS-100 installed at Rothera Station. (e) An LPM installed at Rothera.

\section{Laser-based sensors}

\section{VPF-730 visibility and present weather sensor}

The Biral VPF-730 (Fig. 1c) uses an $850 \mathrm{~nm}$ infrared light source to detect precipitation particles. When a precipitation particle passes through the light beam, it causes a scattering that is recorded by a forward scatter receiver and a backscatter receiver. In addition, different types of precipitation scatter the light differently. For instance, liquid precipitation scatters only a tiny portion of the incident beam, while frozen precipitation can cause a significant backscattering of the light beam. Using this principle, the forward scatter functions to calculate the visibility while the backscatter differentiates the type of precipitation. The VPF-730 can be operated under harsh conditions $\left(-50^{\circ} \mathrm{C}\right.$ to $\left.60^{\circ} \mathrm{C}\right)$. The snow measuring resolution of the VPF-730 is $0.0015 \mathrm{~mm} / \mathrm{h}$. Bellot et al. (2011) used this instrument to study the impact of drifting snow at Cape Prud'homme Station, $5 \mathrm{~km}$ from the Dumont d'Urville Station (Bellot et al. 2011). Their study proposed a calibration method to quantify the surface flux.

\section{PWS-100 scientific present weather sensor}

The PWS-100 (Fig. 1d) is an LBS manufactured by Campbell Scientific. It has a digital signal processor housing unit attached to a laser unit and two sensors perched on a horizontal arm. Each of the sensor heads is $20^{\circ}$ off-axis to the laser unit axis, one in the horizontal plane and the other in the vertical plane. When a precipitation particle falls through the laser beam, it will be detected by the off-axis receiver in the vertical plane, followed by the second receiver in the horizontal plane. The time- lag between detection by the two receivers is used to calculate the fall speed and size of the particle, in addition to the intensity of precipitation. The measuring area for the PWS-100 is $40.0 \mathrm{~cm}^{2}$ per light sheet, with resolution up to $0.0001 \mathrm{~mm}$ precipitation.

\section{LPM}

The LPM (Fig. 1e) uses an infrared laser to measure precipitation particles that pass through its sensors. It consists of a $780 \mathrm{~nm}$ parallel laser source and a receiver made up of a photodiode and a lens. When a precipitation particle passes through the laser path, its presence blocks the laser path, reducing the laser signal that is received by the sensor. On the basis of this information, the instrument computes the sizes of the particles, the falling speed of the particles and the type of precipitation. It differentiates drizzle, rain, snow, soft hail and hail as well as mixed precipitation. The size of snow particles that can be detected ranges from 0.16 to $8.0 \mathrm{~mm}$, while the instrument accuracy varies (60\%-99\%) depending on the type of 
precipitation particles measured. The resolution of this instrument is $0.001 \mathrm{~mm}$.

\section{Reanalysis data sets}

Global reanalysis data sets are produced with a numerical weather prediction model anchored with a variety of meteorological observations (Simmons 2006; Saha et al. 2014; Kobayashi et al. 2015). The global reanalysis data sets used in this study are ERAInt (Dee et al. 2011) and JRA-55 (Kobayashi et al. 2015), alongside a forecast model, the CFSv2 (Yuan et al. 2011) from the NCEP. Reanalysis data sets have vastly improved their spatial resolutions recently - up to $0.7^{\circ}$ for ERA-Int (Dee et al. 2011; Bracegirdle \& Marshall 2012). The resolutions of other reanalysis, such as JRA-55 and forecast model CFSv2, remain quite coarse $\left(0.5^{\circ} \times 0.625^{\circ}\right)$, and questions remain whether reanalysis data sets can deliver reliable precipitation results in comparison to point in situ observations.

ERA-Int (Simmons 2006) is a product of the ECMWF as a replacement for the 40-yr ECMWF Reanalysis. ERA-Int data start from the year 1979 and extend to the present. Significant advances have been incorporated into ERA-Int, including the fourdimensional variational analysis system, which improves the hydrological cycle and the stratospheric circulation and enhanced temporal consistency at different timescales (Simmons 2006). ERA-Int also has a bias-correction for satellite radiances with improved humidity analysis and data management (Dee et al. 2011). The daily precipitation field of $0.5^{\circ} \times 0.5^{\circ}$ was obtained from the ECMWF website. According to Palerme et al. (2017), ERA-Int produces consistent seasonal and interannual variability, and the moisture budget in ERA-Int is closer to equilibrium compared to other data sets. Bromwich et al. (2011) studied and compared precipitation changes since 1989 from five reanalyses and suggested that the ERA-Int gives the most reliable reanalysis for precipitation in the Antarctic (Bromwich et al. 2011).

The JRA-55 data set is produced by the Japan Meteorological Agency as an improvement over its predecessor, JRA-25. Like ERA-Int, JRA-55 incorporates a four-dimensional variational analysis into its system (Kobayashi et al. 2015). It has a bias-correction for satellite radiances and uses greenhouse gases history data, three-dimensional daily ozone data and quality-control information from previous reanalyses (Ebita et al. 2011). Enhanced computational ability also allows the enhanced spatial resolution from T106L40 (nominally $125 \mathrm{~km}$ for JRA-25) to T319L60 (nominally $60 \mathrm{~km}$ ) (Kobayashi et al. 2015). It is important to note that JRA-55 has three different data sets: the Japanese 55-year Reanalysis (JRA-55, ds628.0), the Japanese 55-year Reanalysis using conventional data only (JRA-55C, ds628.2) and the Japanese 55-year Reanalysis AMIP-type Simulation (JRA-55AMIP, ds628.4). While JRA-55C and JRA55AMIP do not extend beyond 1 January 2013, JRA-55 has been updated through July 2016. The daily $0.5^{\circ} \times 0.625^{\circ}$ precipitation field for the location $\left(67^{\circ} \mathrm{S}, 68^{\circ} \mathrm{W}\right)$ was obtained from the Research Data Archive of the National Centre for Atmospheric Research website (JMA 2013). Wang et al. (2016) published a work which suggests that in terms of snow accumulation JRA-55 captures the interannual variability better than ERA-Int at six out of 29 study sites in Antarctica (Wang et al. 2016).

The NCEP's CFSv2 is a semi-coupled forecast model that forces observation from soil moisture and hydrologic states (Saha et al. 2014). In an earlier study, the CFSv2 ensemble means precipitation skill was poor after the first month of reforecast, but overall was better compared to other global forecast models, especially the CFSR (Yuan et al. 2011). Research has shown that the precipitation reforecast errors in the reanalysis can enhance the simulation of soil moisture over central North America with hydrologic models after bias correction (Mo et al. 2012). Dirmeyer et al. (2013) showed that precipitation biases appear in both the reanalysis and reforecast. A recent study evaluating the skills of CFSv2 found that CFSv2 has poor performance over Antarctica for precipitation and 2-metre temperature, as it simulates precipitation anomalies with opposite signal compared to Climate Prediction Center Merged Analysis of Precipitation analysis (Silva et al. 2014).

\section{GPCP 1DD}

The GPCP is an estimation of monthly precipitation based on a combination of rain gauge data, geostationary satellite, low-orbit infrared, passive microwave and surrounding observations (Huffman et al. 1997). It probably comes closest to an observationbased product for the Antarctic (Genthon et al. 2003). The GPCP is derived from merged data from rain gauge stations over land and spaceborne sensors, including Special Sensor Microwave Imager, Special Sensor Microwave Imager/Sounder, and geostationary and polar orbiting infrared imagers and sounders (Huffman et al. 1997; Behrangi et al. 2016). For highlatitude regions such as the Antarctic, precipitation is obtained from satellite sources because of the lack of rain gauge data (Huffman et al. 2009; Trammell et al. 2016). It is one of the most widely used satellite products for Antarctica (Behrangi et al. 2016). There are two versions of the data set: GPCP V2.3 and GPCP 1DD V1.3. The latter version, which will be used in this work, provides precipitation estimates on a $1^{\circ}$ grid over the entire globe on a one-day time-step from 1 October 1996 to 31 October 2015 (at the time 
of writing), while the former uses a $2.5^{\circ} \times 2.5^{\circ}$ grid. The daily $1^{\circ} \times 1^{\circ}$ precipitation GPCP data for Rothera $\left(67^{\circ} \mathrm{S}, 68^{\circ} \mathrm{W}\right)$ was obtained from the Research Data Archive of the National Centre for Atmospheric Research website (Huffman 2016). At the time of writing, the GPCP 1DD product has yet to be used for a precipitation study in Antarctica.

\section{Location and study period}

Rothera station is one of five British Antarctic Survey research stations in the British Antarctic Territory. It is located at Rothera Point $\left(67^{\circ} 33^{\prime} \mathrm{S}, 68^{\circ} 7^{\prime} \mathrm{W}\right)$ on Adelaide Island, Antarctic Peninsula (Fig. 2). It began operation in 1975 and has a wide array of meteorological measurements in operation. The average temperatures at the station in summer range from 0 to $+5^{\circ} \mathrm{C}$ (winter from $-20^{\circ} \mathrm{C}$ to $-5^{\circ} \mathrm{C}$ ), with winds that can reach up to $40 \mathrm{~ms}^{-1}$. For this work, all instruments, except for the UPG-1000, were installed close to one another in order to provide a similar environment for all the instruments. The UPG-1000 was installed behind one of the buildings, at the request of the manufacturer, about $100 \mathrm{~m}$ away from the rest of the instruments, to provide extra shelter against very strong wind events. The measurements from the gauges were logged every minute and made available on the British Antarctic Survey website. For this report, the period of study is from 19 March 2015 to 4 February 2016.

\section{Results}

\section{Precipitation measurement}

Generally, the LBSs are able to detect more precipitation while the TBGs detect less precipitation. The VPF-730 was the most sensitive among the five instruments as it was able to detect more precipitation days than all other instruments: 276 precipitation days from a total of 348 observation days (henceforth denoted as 276/348); followed by the LPM (248/348), the PWS-100 (191/348), the UPG$1000(152 / 348)$ and the $\mathrm{CS} 700 \mathrm{H}(60 / 348)$. The reanalyses, on the other hand, indicated no less than 310 precipitation days during the study period. The reanalyses were also quite consistent with one another, with JRA-55 indicating the most precipitation days (328 precipitation days), followed by ERA-Int (313 precipitation days) and the CFSv2 model (312 precipitation days). An interesting observation that can be drawn from Table 1 is that the number of precipitation days indicated by the GPCP 1DD in autumn 2015 and winter 2015 is closer to the number detected by the precipitation instruments, while the reanalyses indicate a much higher number of precipitation days.

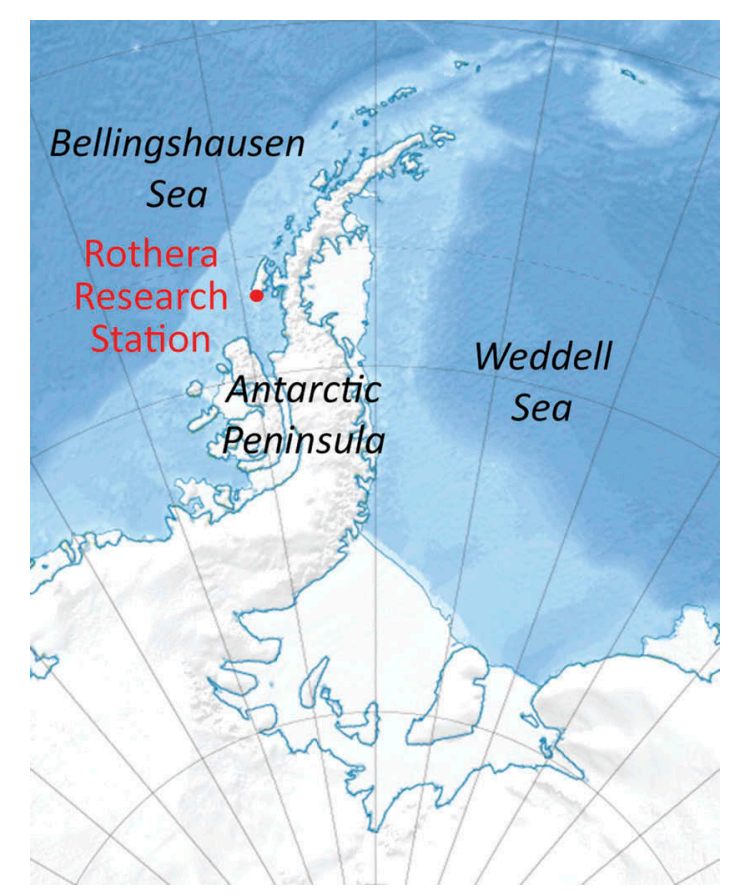

Figure 2. Location of Rothera Station $\left(67^{\circ} 34^{\prime} \mathrm{S}, 68^{\circ} 08^{\prime} \mathrm{W}\right)$. (Modified from a map by Kikos, CC BY-SA 3.0, https://creativecommons.org/licenses/by-sa/3.0, from Wikimedia Commons.)

The LPM registered the highest mean daily precipitation during the study period (mean $=5.76 \mathrm{~mm}$, $\sigma$ [standard deviation] $=14.59 \mathrm{~mm}$ ), followed by the PWS-100 (mean $=5.72 \mathrm{~mm}, \sigma=17.18 \mathrm{~mm}$ ), the VPF-730 $($ mean $=5.10 \mathrm{~mm}, \sigma=11.60 \mathrm{~mm})$, the UPG-1000 (mean $=2.29 \mathrm{~mm}, \sigma=6.36 \mathrm{~mm}$ ) and the $\mathrm{CS} 700 \mathrm{H}$ (mean $=0.459 \mathrm{~mm}, \sigma=15.27 \mathrm{~mm}$ ). The JRA-55 had the highest mean daily precipitation at $13.75 \mathrm{~mm}$, followed by CFSv2 $(6.30 \mathrm{~mm})$ and ERA-Int $(3.97 \mathrm{~mm})$. The GPCP 1DD mean daily precipitation $(2.27 \mathrm{~mm})$ and standard deviation $(3.17 \mathrm{~mm})$ were closer to the instruments than to the reanalyses. It is important to note that the daily mean precipitation amount of the GPCP 1DD and reanalyses are not comparable to the reading from the instruments on account of their coarse resolution, as will be shown later in the monthly and seasonal precipitation section. The precipitation readings from the GPCP 1DD and the reanalyses are more suitable to be compared on a longer time-scale. A $t$-test showed that the differences in mean daily precipitation were insignificant between the LBS instruments. This means that the different LBSs produced results with very minor differences among themselves. In contrast, there were significant differences among the TBGs and among the reanalyses. The GPCP 1DD precipitation was significantly lower than all the data sets $(p<0.05)$, with the sole exception of UPG-1000 ( $p=0.69)$.

Figure 3 shows the monthly precipitation derived from the five precipitation instruments, the reanalyses and the GPCP 1DD (for which the data stop at 
Table 1. Number of precipitation days measured by each instrument (UPG-1000, PWS-100, VPF-730, LPM, CS700H), reanalysis data sets (ERA-Int, JRA-55), CFSv2 model and the GPCP during the study period (19 March 2015 to 4 February 2016). Note: The GPCP data were available up to 31 October 2015 at the time of writing.

\begin{tabular}{lcccccccccc}
\hline & UPG-1000 & PWS-100 & VPF-730 & LPM & CS700H & ERA-Int & CFSv2 & JRA-55 & GPCP \\
\hline Autumn 2015 & 40 & 43 & 55 & 53 & 24 & 68 & 66 & 71 & 53 \\
Winter 2015 & 33 & 51 & 74 & 61 & 6 & 84 & 78 \\
Spring 2015 & 44 & 57 & 82 & 74 & 19 & 85 & 85 \\
Summer 2015/16 & 35 & 40 & 65 & 60 & 11 & 76 & 89 & 44 \\
Total & 152 & 191 & 276 & 248 & 60 & 313 & 312 & 32 \\
\hline
\end{tabular}

${ }^{a}$ Not available.

October 2015). One important observation from Fig. 3 is the high precipitation amount registered by the PWS-100 in August 2015 due to the extreme precipitation on 4-6 August 2015. The details of this extreme event will be discussed in the case studies and discussion sections. Among the instruments, the LPM had the highest mean monthly precipitation (154.94 mm), followed by the PWS-100 (153.9 mm), the VPF-730 (137.33 $\mathrm{mm})$, the UPG-1000 $(61.68 \mathrm{~mm})$ and the $\mathrm{CS} 700 \mathrm{H}(12.37 \mathrm{~mm})$. Maximum precipitation occurred in the months of August (winter 2015) and October (spring 2015), while minimum precipitation occurred in the month of May (autumn 2015). ERA-Int and CFSv2 produced results that closely match the instrumental precipitation measurement. JRA-55, however, showed a much higher precipitation compared to the other reanalysis and precipitation instruments (except for August). JRA-55 also yielded the highest monthly mean precipitation $(370.10 \mathrm{~mm})$, followed by CFSv2 $(169.45 \mathrm{~mm})$ and ERA-Int $(106.82 \mathrm{~mm})$. The mean monthly precipitation for the GPCP $1 \mathrm{DD}$ is $64.51 \mathrm{~mm}$, which is closer to the measurements made by the instruments. The resolution of the reanalysis data sets and the GPCP 1DD plays a large role in the readings. For the reanalyses, the coarse resolution does not capture the complicated terrain of the Antarctic Peninsula surrounding Rothera, especially the high elevation on Adelaide Island, and therefore does not accurately replicate the orographic effect. For the GPCP 1DD, as with all merged-satellite precipitation products, the inherent difficulty of converting sparse satellite data into meaningful precipitation estimates confined in a high-resolution grid is caused by several factors. The geostationary infrared detector senses the changes of clouds rather than precipitation itself, and surface precipitation is determined indirectly through the measurement of brightness temperature via microwave and infrared satellite. These proxies of precipitation are then fed into an algorithm that includes cloud-reflected energy from radar and sparse, in situ direct gauge measurements to produce the final GPCP precipitation estimate (Huffman et al. 1997). Moreover, satellite products employed in the GPCP algorithm tend to miss light precipitation events (Behrangi et al. 2012; Behrangi et al. 2014).

A correlation study was used to determine the similarity in terms of temporal pattern between two sets of data. It is important to note that a significant correlation shows that two data sets have a degree of similarity in terms of data pattern and

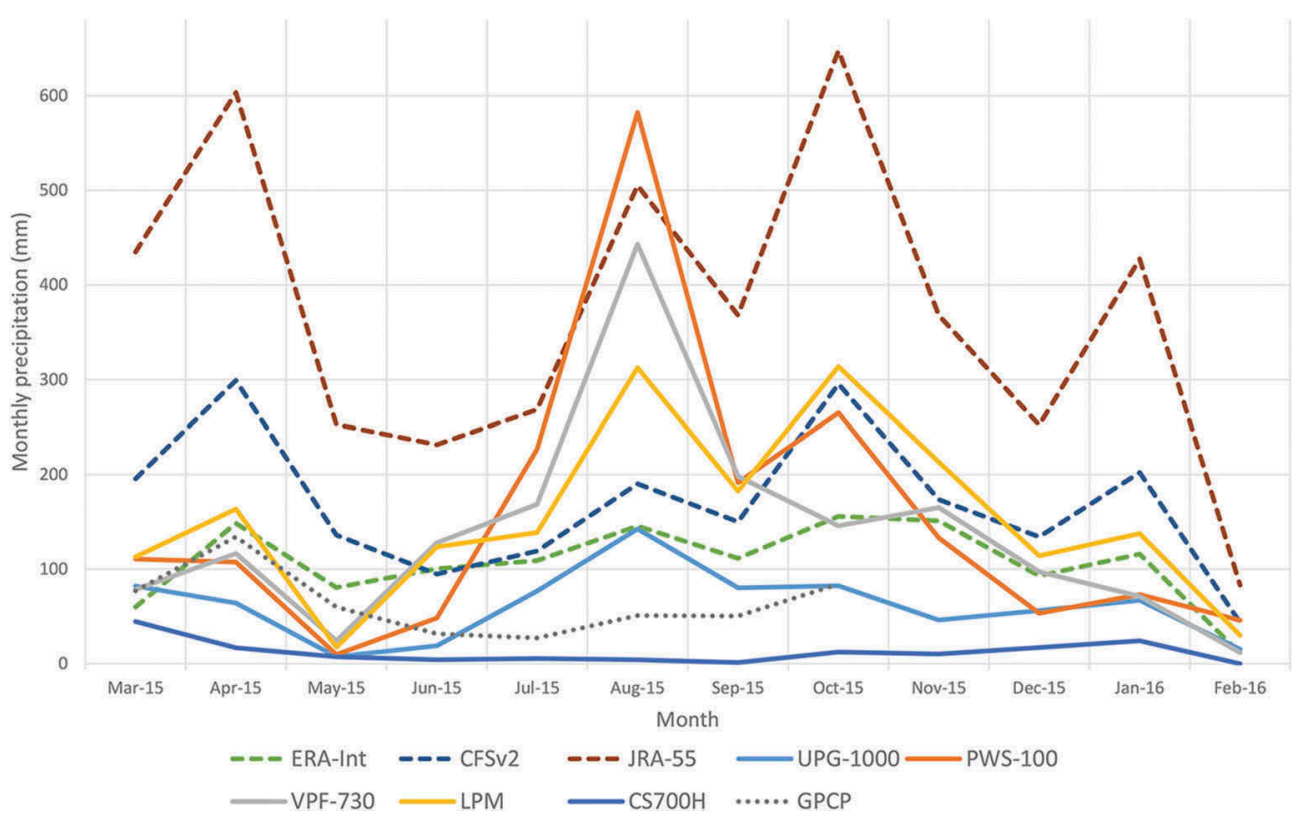

Figure 3. Monthly precipitation for all the precipitation instruments, reanalyses, model and the GPCP 1DD. 
trend, but are not necessarily similar in terms of magnitude or precipitation amount. A correlation index (shown in Table 2) shows how consistent two data sets are with one another, and therefore whether they are useful for the purpose of validation. The correlation indices between the monthly precipitation logged by the instruments, reanalyses and the GPCP 1DD are tabulated in Table 2 . Table 2 shows that all the reanalyses have more than +0.50 correlation with at least one of the precipitation instruments. From another perspective, with the exception of the $\mathrm{CS700H}$, the instruments show correlation indices over +0.60 with at least one reanalysis. JRA-55, for instance, has $\mathrm{a}+0.6491$ correlation with the UPG-1000 and +0.4880 correlation with the PWS-100. The GPCP 1DD has high correlation with reanalysis JRA-55 (+0.7637) and model CFSv2 (+0.8811), while having correlation less than +0.50 with the precipitation instruments.

\section{Seasonal variation}

All instruments, except the $\mathrm{CS700H}$, and reanalyses show that spring (September-November) 2015 had the most precipitation days, while the day with the least precipitation was evenly distributed between winter (June-August) 2015 and autumn (March-May) 2015 (Table 1). However, Fig. 4 shows that the precipitation amount for winter exceeded that of spring. Precipitation seasonal means and standard deviations are tabulated in Table 3. The seasonal mean precipitation measured by the VPF-730 and the PWS-100 were closest to the value obtained from ERA-Int for autumn 2015, spring 2015 and summer 2015/16. The GPCP 1DD, on the other hand, was closest to precipitation values obtained from the UPG-1000 in winter 2015 and spring 2015. The LPM and the PWS-100 yielded extremely high precipitation readings, resulting in high precipitation means and standard deviations. These anomalies will be further discussed in a later section.

\section{Case studies}

To gain a better understanding of the operation of the different instruments and the environmental factors that affect precipitation measurement, the case studies of precipitation measurement presented below compare the precipitation measurements from the different instruments and reanalyses against wind speed and temperature data obtained from an automated weather station at Rothera. For the case studies, periods with strong wind and precipitation days were chosen: 19 March 2015 to 5 April 2015; 27 July 2015 to 18 August 2015; and 21 December 2015 to 5 January 2016.

\section{March 2015 to 6 April 2015}

This period was chosen because all the instruments were active and performing at their best. Figure 5 shows the daily mean temperature, daily mean wind speed and daily precipitation from 19 March 2015 to 6 April 2015. As expected, all readings from the instruments are positively correlated with one another $(>+0.80)$ and with those from the reanalyses $(>+0.70)$. The GPCP 1DD has a correlation ranging from +0.4328 to +0.6127 with the precipitation instruments and reanalyses. More interestingly, all the precipitation data sets are positively correlated (ranging from +0.4844 to +0.7078 ) with the daily wind speed, and slightly less positively correlated (ranging from +0.2942 to +0.5060$)$ with daily temperature. This shows that wind fluctuations had an important effect on the amount of precipitation measured. The instruments' precipitation measurements on 21 March 2015, 29-30 March 2015 and 5 April 2015 were much lower compared to those of the reanalyses.

The wind speed on 24 March 2015 exceeded $12 \mathrm{~ms}^{-1}$. In spite of the strong wind, the TBGs captured significant amounts of precipitation (up to $56.0 \mathrm{~mm}$ and $33.2 \mathrm{~mm}$ for the UPG-1000 and the $\mathrm{CS700H}$, respectively) - higher values than the precipitation measured by ERA-Int (16.1 mm). JRA-55 registered close to $120.0 \mathrm{~mm}$ of precipitation on 24 March 2015, which is more than seven times higher than the ERA-Int precipitation readings. It is worth

Table 2. Correlation table for the precipitation measured by the precipitation instruments (UPG-1000, PWS-100, VPF-730, LPM, CS700H), reanalysis data sets (ERA-Int, JRA-55), CFSv2 model and GPCP. Numbers in boldface are values that are significant $a=95 \%(p \leq 0.05)$.

\begin{tabular}{|c|c|c|c|c|c|c|c|c|c|}
\hline & UPG-1000 & PWS-100 & VPF-730 & LPM & $\mathrm{CS} 700 \mathrm{H}$ & ERA-Int & CFSv2 & JRA-55 & GPCP \\
\hline UPG-1000 & 1.00 & 0.87 & 0.81 & 0.78 & 0.19 & 0.52 & 0.50 & 0.65 & 0.056 \\
\hline PWS-100 & & 1.00 & 0.94 & 0.80 & -0.21 & 0.51 & 0.30 & 0.49 & -0.15 \\
\hline VPF-730 & & & 1.00 & 0.78 & -0.28 & 0.59 & 0.22 & 0.41 & -0.25 \\
\hline LPM & & & & 1.00 & -0.066 & 0.81 & 0.62 & 0.76 & 0.12 \\
\hline $\mathrm{CS} 700 \mathrm{H}$ & & & & & 1.00 & -0.066 & 0.42 & 0.36 & 0.45 \\
\hline ERA-Int & & & & & & 1.00 & 0.72 & 0.76 & 0.35 \\
\hline CFSv2 & & & & & & & 1.00 & 0.97 & 0.88 \\
\hline JRA-55 & & & & & & & & 1.00 & 0.76 \\
\hline GPCP & & & & & & & & & 1.00 \\
\hline
\end{tabular}




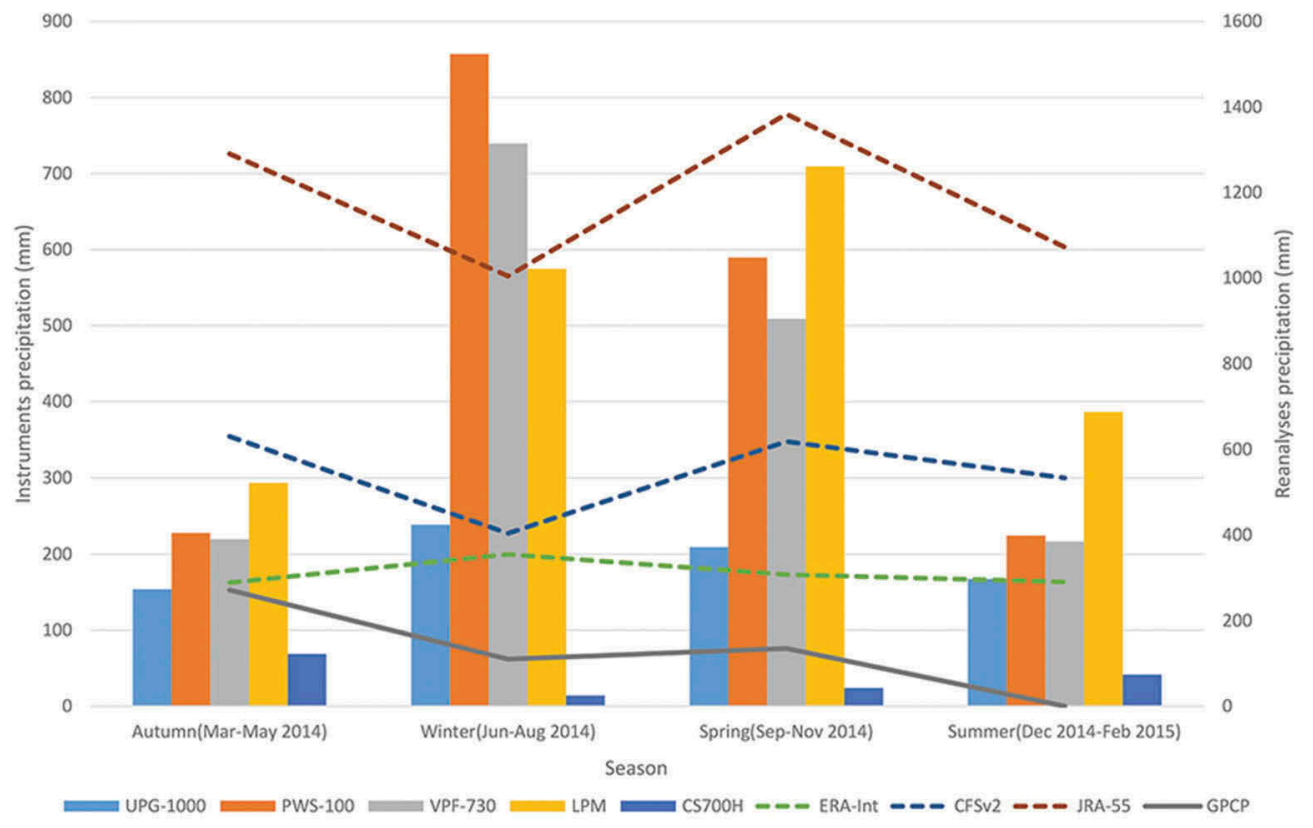

Figure 4. Seasonal precipitation for the precipitation instruments, reanalysis data sets and model.

Table 3. Mean and standard deviation of precipitation for autumn, winter, spring and summer.

\begin{tabular}{|c|c|c|c|c|c|c|c|c|}
\hline & \multicolumn{2}{|c|}{$\begin{array}{c}\text { Autumn } \\
\text { (Mar-May 2015) }\end{array}$} & \multicolumn{2}{|c|}{$\begin{array}{c}\text { Winter } \\
\text { (Jun-Aug 2015) }\end{array}$} & \multicolumn{2}{|c|}{$\begin{array}{c}\text { Spring } \\
\text { (Sep-Nov 2015) }\end{array}$} & \multicolumn{2}{|c|}{$\begin{array}{c}\text { Summer } \\
\text { (Dec 2015-Feb 2016) }\end{array}$} \\
\hline & $\begin{array}{l}\text { Mean } \\
(\mathrm{mm})\end{array}$ & $\begin{array}{l}\text { Standard deviation } \\
\qquad(\mathrm{mm})\end{array}$ & $\begin{array}{l}\text { Mean } \\
(\mathrm{mm})\end{array}$ & $\begin{array}{l}\text { Standard deviation } \\
(\mathrm{mm})\end{array}$ & $\begin{array}{l}\text { Mean } \\
(\mathrm{mm})\end{array}$ & $\begin{array}{l}\text { Standard deviation } \\
\qquad(\mathrm{mm})\end{array}$ & $\begin{array}{l}\text { Mean } \\
(\mathrm{mm})\end{array}$ & $\begin{array}{c}\text { Standard deviation } \\
(\mathrm{mm})\end{array}$ \\
\hline UPG-1000 & 2.08 & 6.83 & 2.59 & 8.06 & 2.30 & 5.38 & 1.84 & 4.60 \\
\hline $\mathrm{CS} 700 \mathrm{H}$ & 0.93 & 4.00 & 0.15 & 0.63 & 0.264 & 0.896 & 0.63 & 2.37 \\
\hline VPF-730 & 3.00 & 7.00 & 8.04 & 15.84 & 5.59 & 12.19 & 2.38 & 4.97 \\
\hline PWS-100 & 3.08 & 7.51 & 9.42 & 26.75 & 6.48 & 15.12 & 2.47 & 6.76 \\
\hline LPM & 4.14 & 8.83 & 6.61 & 16.98 & 8.06 & 18.84 & 4.25 & 9.59 \\
\hline JRA-55 & 17.44 & 21.63 & 10.92 & 16.63 & 15.20 & 19.02 & 11.79 & 14.09 \\
\hline ERA-Int & 3.90 & 4.42 & 3.86 & 5.22 & 4.60 & 4.82 & 3.19 & 4.75 \\
\hline CFSv2 & 8.52 & 9.05 & 4.39 & 5.82 & 6.80 & 6.88 & 5.87 & 6.54 \\
\hline GPCP & 3.67 & 4.27 & 1.19 & 1.87 & 2.21 & 2.48 & - & - \\
\hline
\end{tabular}

noting that precipitation is the result of the interaction between various meteorological parameters including wind, pressure, temperature and cyclone activity - and temperature is but a contributing factor in this complex cycle. Simple correlations between temperature and precipitation alone may not be sufficient to present the complexity of the entire precipitation cycle.

\section{July 2015 to 18 August 2015}

These dates were chosen because of the precipitation days and a strong wind event from 4 to 6 August 2015. Similar to the previous case study, the precipitation measurements are positively correlated with both temperature (ranging from +0.4144 to +0.5272 ) and wind speed (ranging from +0.6060 to +0.8110 ), with the sole exception of the LPM. The reading for the LPM during this period was removed because of a blockage to the instrument's laser head. Also similar to the previous case study, the CFSv2 has a positive correlation $(+0.8264)$ with wind speed. The reanalyses data sets showed high amounts of precipitation while the actual instruments registered only very small amounts of precipitation. For this period, the GPCP 1DD is positively correlated with the UPG-1000 (+ 0.7061), the PWS-100 (+ 0.7657), the VPF-730 $(+0.8504)$, the CFSv2 $(+0.7234)$ and the JRA-55 (+ 0.7092).

As can be seen in Fig. 6, there were three strong wind episodes from 4 to 6 August 2015. Three of five instruments detected the most precipitation on 5 August, whereas the reanalyses registered the most precipitation on 4 August, and again on 7 August, when all the instruments registered low precipitation. The strong wind events on 4-6 and 10-11 August caused the LBSs to report high precipitation readings. As mentioned above, the LPM laser's head was blocked by snow on 4-6 August, causing the reading to become exceedingly high (over $1000 \mathrm{~mm}$ ). Comparing the instruments' results revealed the inconsistency of the LPM reading, confirming the presence of error. For the 10-11 August case, the LPM was fully functional but did not indicate any precipitation, while the readings registered by the PWS-100 and the VPF-730 were high. It should be noted that the $\mathrm{CS} 700 \mathrm{H}$ suffered a 
(a) mean daily temperature 19 March 2015-6 April 2015

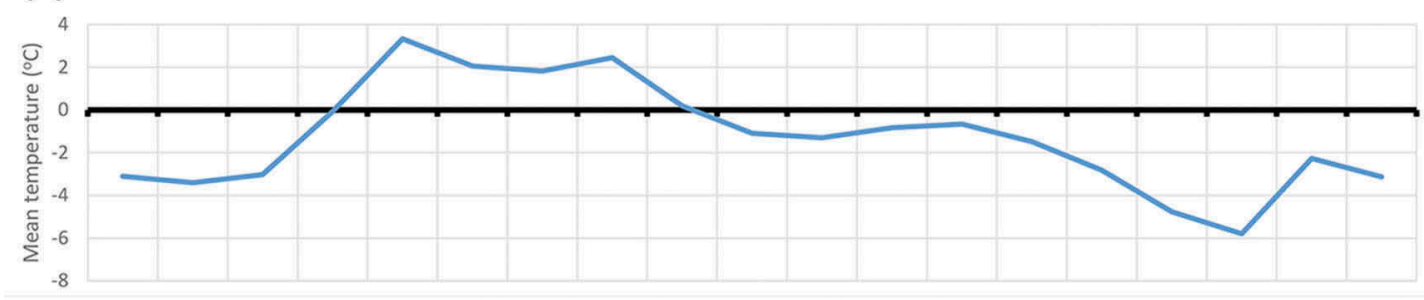

(b) mean daily wind speed 19 March 2015-6 April 2015

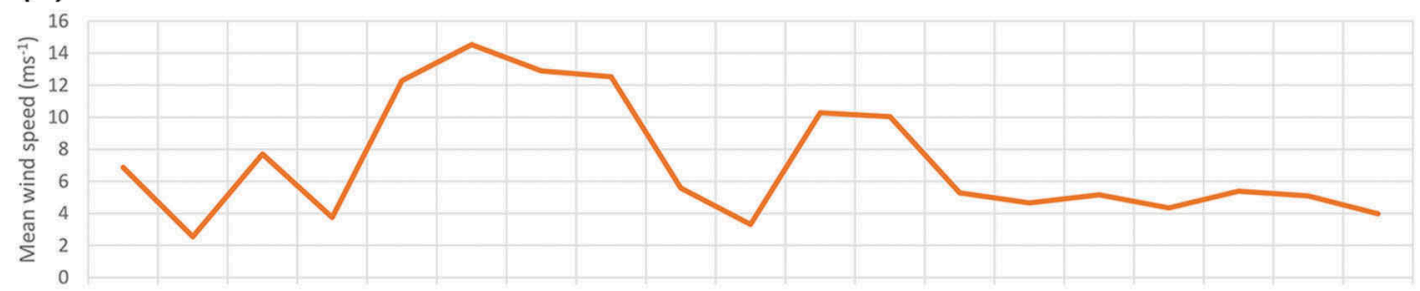

(c) precipitation 19 March 2015-6 April 2015

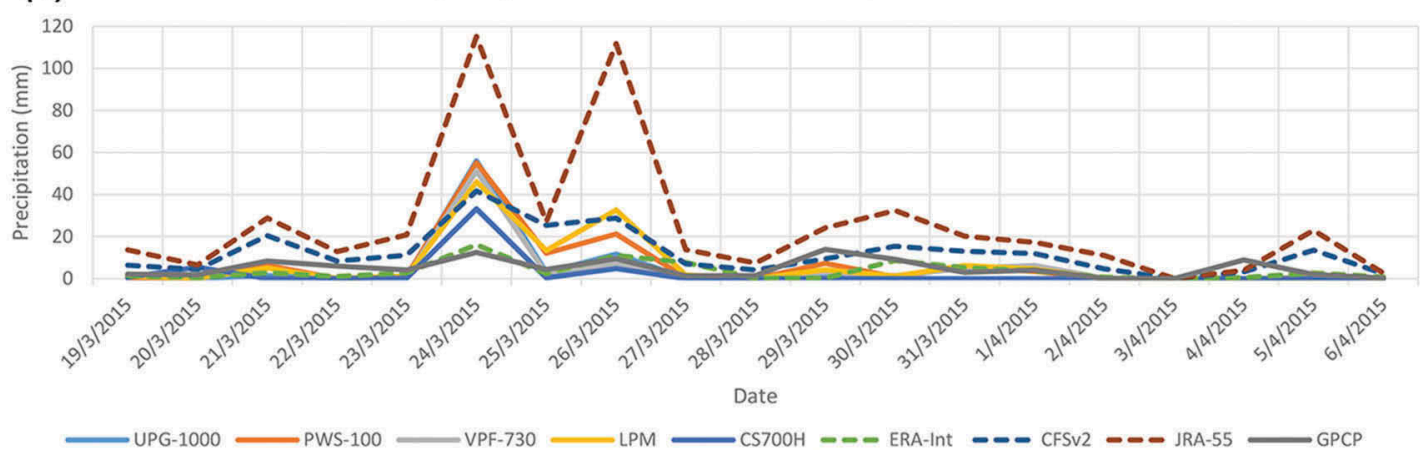

Figure 5. (a) Daily temperature, (b) mean wind speed and (c) daily precipitation at Rothera 19 March 2015 to 6 April 2015 . The wind and temperature data were obtained via automated sensors connected to a CR1000 datalogger at Rothera.

malfunction during this period and did not deliver reliable readings.

\section{December 2015 to 5 January 2016}

For this period, temperature is positively correlated with the instruments (up to +0.5550 ) and the reanalyses $(+0.4951$ to +5562$)$. Wind speed, on the other hand, has a low correlation with the reanalyses and model (ERA-Int: + 0.3538; CFSv2: + 0.2019; JRA-55: $+0.1554)$. An important observation that can be drawn from Fig. 7 is the precipitation measurement by the VPF-730 on 23-24 December 2015, which happened on two relatively warm, windy days when all other instruments registered no precipitation readings, but the reanalyses did.

Another interesting observation of the influence of wind on the reanalyses can be seen during the 28 December 2015 to 4 January 2016 period: all the instruments showed an increase in precipitation from 1 to 3 January 2016, with the most precipitation measured on 2 January 2016. The two reanalyses, on the other hand, showed different precipitation patterns. The precipitation of the reanalyses increased with increasing wind speed, especially during the period 29 December 2015 to 1 January 2016 (Fig. 7). The different reanalyses registered peak precipitation on different days: the ERA-Int peak precipitation occurred on 30 December, while the JRA-55 and CFSv2 peak precipitation occurred on 3 January. ERA-Int is widely considered to be the most accurate reanalysis for studying precipitation in the Antarctic (Bromwich et al. 2011). However, while all the in situ instruments in our study showed consistent results on 2 January 2016, the ERA-Int suggested a different picture (Fig. 7).

\section{Discussion}

\section{The effects of wind}

Our study indicates that wind has a profound effect on the TBGs and the LBSs. The TBGs are generally less sensitive to precipitation compared to the LBSs, which can be attributed to effects of the funnel and the nature of snow particles in Antarctica. In the Antarctic, snow particles consist of ice crystals that can be very small and light (Lachlan-Cope et al. 2001), and therefore susceptible to even the slightest breeze. It is not uncommon to see snow particles travelling horizontally or even upward in strong wind. Therefore, the TBGs, which rely heavily on gravitational pull to bring 
(a) mean daily temperature 27 July 2015-18 August 2015

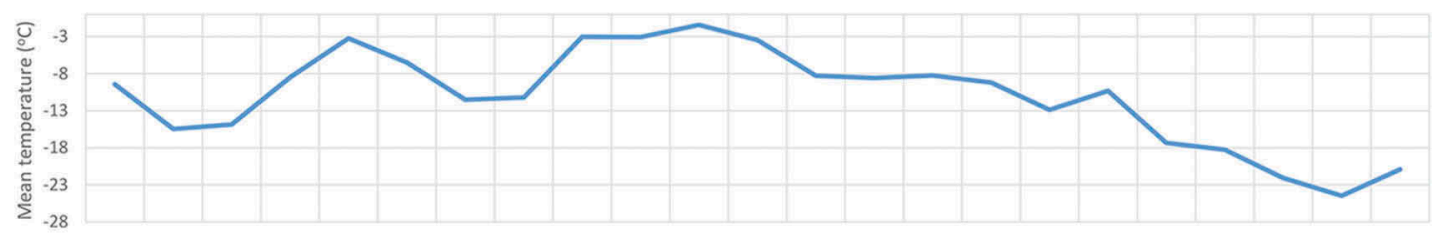

(b) mean daily wind speed 27 July 2015-18 August 2015

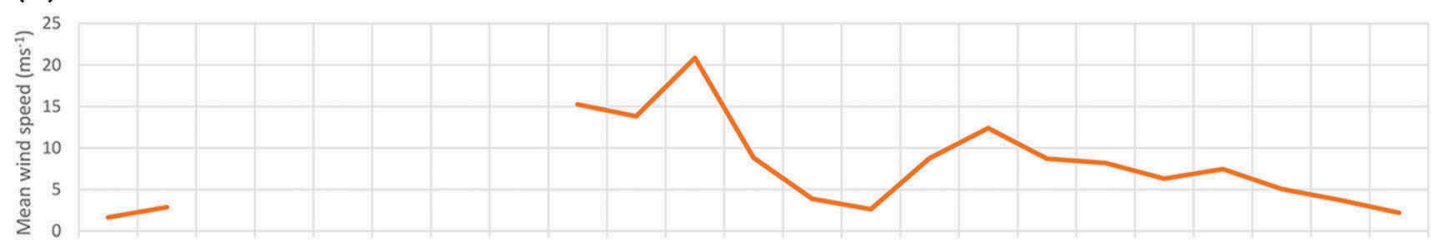

(c) precipitation 27 July 2015-18 August 2015

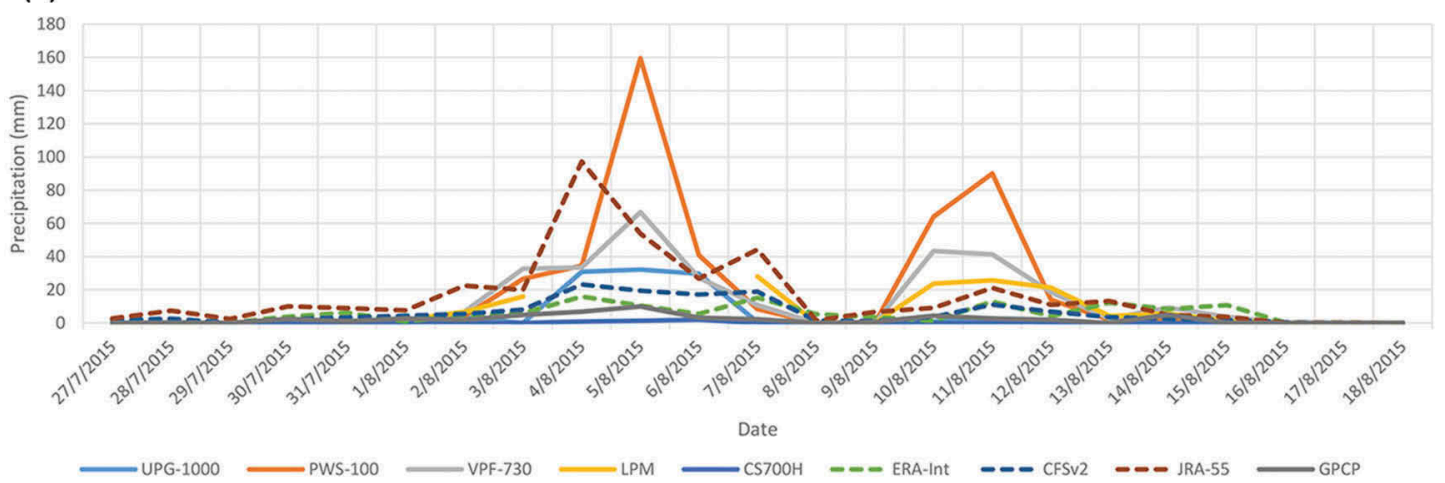

Figure 6. (a) Daily temperature, (b) mean wind speed and (c) daily precipitation at Rothera 27 July 2015 to 18 August 2015 . The wind and temperature data were obtained via automated sensors connected to a CR1000 datalogger at Rothera.

precipitation particles into the funnel, can only be efficient under low wind conditions. Moreover, wind tends to blow the snow particles, even those already falling down the funnel, out of the snow gauge. Folland (1988) proposed that the design of precipitation gauges would cause an updraft at the leading edge, creating an upward deflection of snow particles (Folland 1988). One method to reduce the effect of wind is to instal a wind shield around the TBG. One of the most widely used wind shields is the Alter shield (Alter 1937). Installation of the Alter shield helps to reduce the flow speed and distortion around the precipitation instrument, improving snow detection (Rasmussen et al. 2012).

Wind also affects the LBSs by blowing the snow particles in multiple directions, sometimes travelling up and down or in a loop. This could cause a snow particle to cross the beam of the sensor multiple times, introducing error to the measurement. Moreover, strong wind can blow ground snow towards an LBS, which reads every particle that passes through the beam path, resulting in false readings. During periods of low wind, the precipitation measurements given by the LBSs were very close to the value given by the GPCP. During strong wind events, the GPCP 1DD precipitation values were relatively low.
This could be caused by the GPCP's inability to capture the effect of wind as accurately as in situ instruments. Wind effects interfere with our ability to accurately record precipitation in Antarctica.

\section{Instrumental problems}

One of the main observations of our study was the failure of the $\mathrm{CS} 700 \mathrm{H}$ to function properly and deliver reliable precipitation measurements. After the first month of observations, a significant difference between the data obtained from the $\mathrm{CS} 700 \mathrm{H}$ and the other instruments was observed. While the five gauges did not yield precisely the same precipitation amounts, the results obtained by the $\mathrm{CS} 700 \mathrm{H}$ were markedly lower than that of all other instruments. An inspection revealed that the heating element of the $\mathrm{CS} 700 \mathrm{H}$ required higher-thanexpected power input in order to function properly. Based on its specification, the $\mathrm{CS} 700 \mathrm{H}$ requires 10 to 30 $\mathrm{V}_{\mathrm{DC}}$ or 12 to $28 \mathrm{~V}_{\mathrm{AC}}$, while the PWS-100 requires only 9 to $24 \mathrm{~V}_{\mathrm{DC}}$ (or 9 to $16 \mathrm{~V}_{\mathrm{DC}}$ with CS215-PWS Temperature and $\mathrm{RH}$ sensor) and the LPM $12 \mathrm{~V}_{\mathrm{DC}}$ Version requires an additional heater $230 \mathrm{~V}_{\mathrm{AC}} / 150 \mathrm{VA}$. The $\mathrm{CS} 700 \mathrm{H}$ can be a power-saving option as it can turn on its heater only when needed. Subsequent repair was insufficient to keep the instrument working properly, 
(a) mean daily temperature 21 Dec 2015-5 January 2016

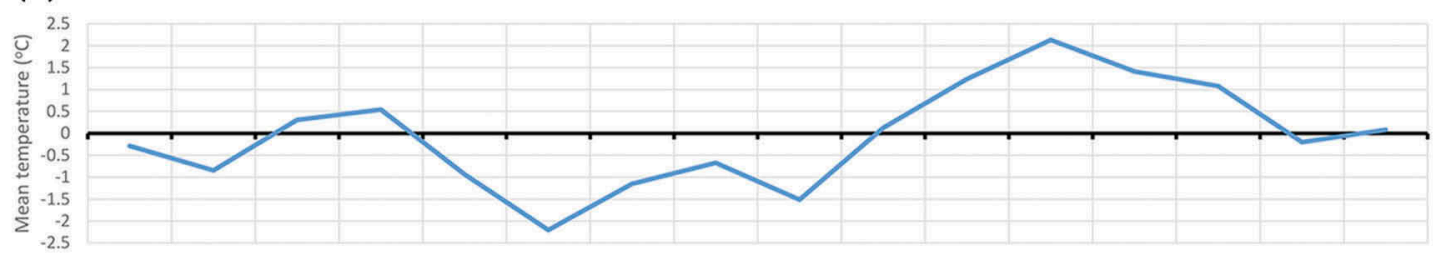

(b) mean daily wind speed 21 December 2015-5 January 2016

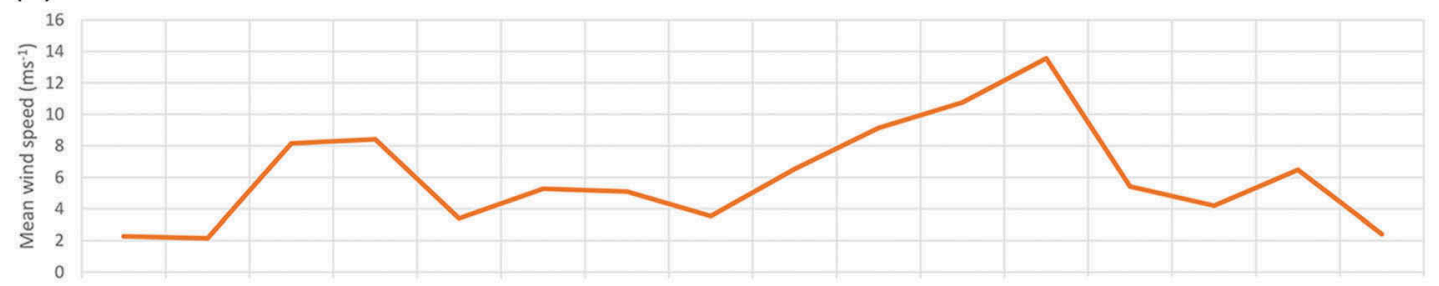

(c) precipitation 21 December 2015-5 January 2016

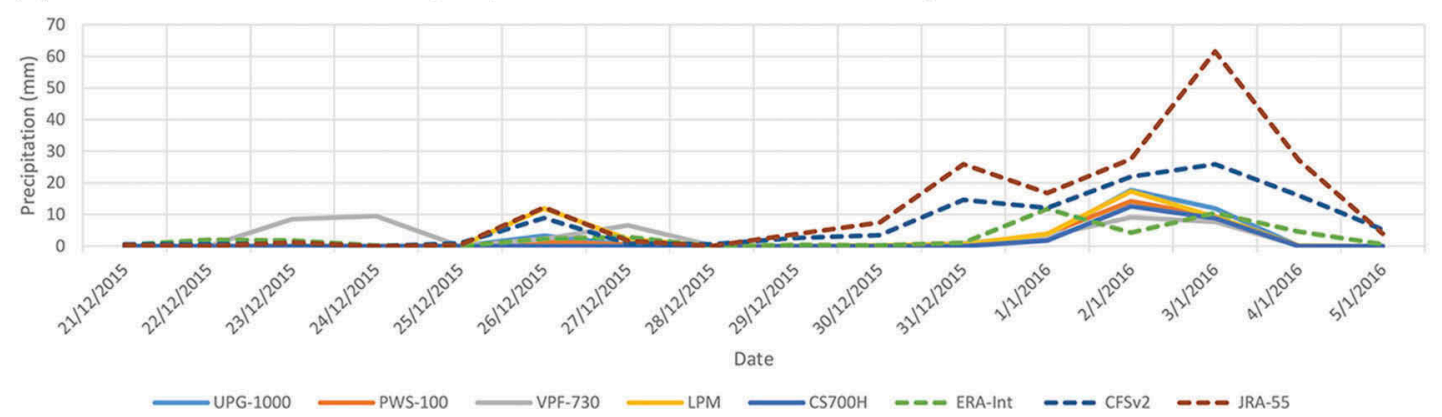

Figure 7. (a) Daily temperature, (b) mean wind speed and (c) daily precipitation at Rothera 21 December 2015 to 5 January 2016. The wind and temperature data were obtained via automated sensors connected to a CR1000 data logger at Rothera.

which accounts for the different results from this instrument compared to other instruments.

The LBS also had problems in the harsh environment of the Antarctic. There were multiple instances (10 readings) when blowing snow blocked the sensor head of the LPM, causing unrealistic readings. At one point the error registered by the LPM was $1317.84 \mathrm{~mm}$ in a single day. After removing observations that had registered blockage of the sensor head by snow, the daily mean precipitation for the LPM becomes $5.83 \mathrm{~mm}$, a marked reduction compared to the original reading and a value much closer to the readings reported by the VPF-730, the PWS-100 and the UPG-1000. The LPM has an internal heating feature similar to that of the UPG-1000 and the $\mathrm{CS} 700 \mathrm{H}$, as mentioned above. However, the LPM installed at Rothera did not have the internal heater turned on.

\section{Heating feature}

One of the major problems observed on the $\mathrm{CS} 700 \mathrm{H}$ was the formation of ice that blocked the funnel. This blocking did not happen to the UPG-1000. The two instruments use the same working principle and heating element, but the UPG-1000 has a wide, bowl-like funnel with a gentle slope that allows the snow particles that fall into it to slide slowly into the tipping bucket, absorbing sufficient heat along the way to ensure that freezing does not occur, whereas the $\mathrm{CS} 700 \mathrm{H}$ has a much narrower design and a funnel that slopes heavily towards the tipping bucket. Under heavy precipitation conditions, a snow particle that falls into the $\mathrm{CS} 700 \mathrm{H}$ slides quickly towards the tipping bucket and can refreeze before dropping into the tipping bucket. The narrower design of the $\mathrm{CS} 700 \mathrm{H}$ could also be the reason why the $\mathrm{CS} 700 \mathrm{H}$ measured less precipitation compared to the UPG-1000 when the two instruments were active during the first month of operation.

The heating function of the TBGs can also be a disadvantage. The air of the Antarctic is relatively dry compared to the mid-latitudes and tropics. Water, therefore, can evaporate easily under the right conditions. While the process of evaporation is not entirely temperature dependent, the rate of evaporation is positively correlated with temperature. When the heating function of the $\mathrm{CS} 700 \mathrm{H}$ is turned on - when it is meant to maintain the temperature of funnel at around $10^{\circ} \mathrm{C}$ - it could possibly provide enough heat not only to melt, but also evaporate, the precipitation. The UPG-1000, on the other hand, turns on the heater when the ambient temperature approaches zero and 
maintains the temperature at around $3^{\circ} \mathrm{C}$. This would result in much higher loss to evaporation in the $\mathrm{CS} 700 \mathrm{H}$, leading to inaccurate measurements. The heating element on the LBSs does not cause a loss in measured precipitation because it functions only to prevent snow from blocking the sensor head and the measured snow particles are not in direct contact with the heated sensor head.

\section{Conclusion}

Quantifying precipitation in Antarctica involves unique challenges, such as wind and technical difficulties associated with the harsh environment. This study compared a variety of precipitation measurements in Antarctica, including field instruments, satellite data and available reanalysis data sets. Among the instruments, the TBGs were generally less sensitive than the LBSs. The most sensitive LBS (VPF-730) registered 276 precipitation days out of a total of 348 days, while the most sensitive TBG (UPG-1000) detected 152 precipitation days. The LPM had the highest mean daily precipitation during the study period, followed by other LBSs - the PWS-100 and the VPF-730 (5.102 mm) - and the TBGs UPG-1000 and CS700H. Case studies of the precipitation results and seasonal accumulation results show that the VPF-730 may be the most reliable precipitation instrument. The precipitation amounts given by the reanalyses were significantly correlated with wind speed. JRA-55 was the most affected by wind speed, giving precipitation amounts significantly higher than the other reanalysis as well as instrument measurements. The comparison between the instruments, reanalyses, model and the GPCP 1DD shows that the GPCP 1DD results were closest to CFSv2, while for the instruments the measurements from GPCP 1DD were closest to the UPG-1000. The LPM and the $\mathrm{CS} 700 \mathrm{H}$ experienced instrumental error during the study, which caused precipitation readings to be exceedingly high and low, respectively. Installing multiple LBSs in different locations (in close proximity) can help identify inconsistencies in the readings.

\section{Acknowledgements}

The authors wish to thank the British Antarctic Survey for the provision of precipitation data from Rothera.

\section{Disclosure statement}

No potential conflict of interest was reported by the authors.

\section{Funding}

This work was funded by University of Malaya Research, grant RP002B-13SUS; Ministry of Science Technology and Innovation (MOSTI) flagship grant FP1213E037.

\section{ORCID}

Malcolm S.Y. Tang (D) http://orcid.org/0000-0002-95362009

\section{References}

Agosta C., Fettweis X. \& Datta R. 2015. Evaluation of the CMIP5 models in the aim of regional modelling of the Antarctic surface mass balance. Cryosphere 9, 23112321.

Alter J.C. 1937. Shielded storage precipitation gages. Monthly Weather Review 65, 262-265.

Behrangi A., Christensen M., Richardson M., Lebsock M., Stephens G., Huffman G.J., Bolvin D., Adler R.F., Gardner A. \& Lambrigtsen B. 2016. Status of high-latitude precipitation estimates from observations and reanalyses. Journal of Geophysical Research-Atmospheres 121, 4468-4486.

Behrangi A., Lebsock M., Wong S. \& Lambrigtsen B. 2012. On the quantification of oceanic rainfall using spaceborne sensors. Journal of Geophysical ResearchAtmospheres 117, D20105, doi: 10.1029/2012JD017979.

Behrangi A., Tian Y., Lambrigtsen B.H. \& Stephens G.L. 2014. What does CloudSat reveal about global land precipitation detection by other spaceborne sensors? Water Resources Research 50, 4893-4905.

Bellot H., Trouvilliez A., Naaim-Bouvet F., Genthon C. \& Gallee H. 2011. Present weather-sensor tests for measuring drifting snow. Annals of Glaciology 52, 176-184.

Benning J. \& Yang D. 2005. Adjustment of daily precipitation data at Barrow and Nome Alaska for 1995-2001. Arctic, Antarctic, and Alpine Research 37, 276-283.

Bindschadler R., Choi H., Shuman C. \& Markus T. 2005. Detecting and measuring new snow accumulation on ice sheets by satellite remote sensing. Remote Sensing of Environment 98, 388-402.

Bracegirdle T.J. \& Marshall G.J. 2012. The reliability of Antarctic tropospheric pressure and temperature in the latest global reanalyses. Journal of Climate 25, 71387146.

Bromwich D.H., Guo Z.C., Bai L.S. \& Chen Q.S. 2004. Modeled Antarctic precipitation. Part I: spatial and temporal variability. Journal of Climate 17, 427-447.

Bromwich D.H., Nicolas J.P. \& Monaghan A.J. 2011. An assessment of precipitation changes over Antarctica and the Southern Ocean since 1989 in contemporary global reanalyses. Journal of Climate 24, 4189-4209.

Cohen L. \& Dean S. 2013. Snow on the Ross Ice Shelf: comparison of reanalyses and observations from automatic weather stations. The Cryosphere 7, 1399-1410.

Dee D.P., Uppala S.M., Simmons A.J., Berrisford P., Poli P., Kobayashi S., Andrae U., Balmaseda M.A., Balsamo G. \& Bauer P. 2011. The ERA-Interim reanalysis: configuration and performance of the data assimilation system. Quarterly Journal of the Royal Meteorological Society 137, 553-597.

Dirmeyer P.A. 2013. Characteristics of the water cycle and land-atmosphere interactions from a comprehensive 
reforecast and reanalysis data set: cFSv2. Climate Dynamics 41, 1083-1097.

Dutton M., Jenkins T. \& Strangeways I. 2008. A heated aerodynamic universal precipitation gauge. Paper presented at TECO-2008: WO Technical Conference on Meteorological and Environmental Instruments and Methods of Observation, 27-29 November, St. Petersburg.

Ebita A., Kobayashi S., Ota Y., Moriya M., Kumabe R., Onogi K., Harada Y., Yasui S., Miyaoka K. \& Takahashi K. 2011. The Japanese 55-year reanalysis "JRA-55": an interim report. Sola 7, 149-152.

Folland C.K. 1988. Numerical-models of the raingauge exposure problem, field experiments and an improved collector design. Quarterly Journal of the Royal Meteorological Society 114, 1485-1516.

Fyfe J.C., Gillett N.P. \& Marshall G.J. 2012. Human influence on extratropical Southern Hemisphere summer precipitation. Geophysical Research Letters 39, L23711, doi: 10.1029/2012GL054199.

Genthon C., Krinner G. \& Sacchettini M. 2003. Interannual Antarctic tropospheric circulation and precipitation variability. Climate Dynamics 21, 289-307.

Huffman G.J., Adler R.F., Arkin P., Chang A., Ferraro R., Gruber A., Janowiak J., McNab A., Rudolf B. \& Schneider U. 1997. The global precipitation climatology project (GPCP) combined precipitation dataset. Bulletin of the American Meteorological Society 78, 5-20.

Huffman G.J., Adler R.F., Bolvin D.T. \& Gu G. 2009. Improving the global precipitation record: GPCP version 2.1. Geophysical Research Letters 36, L17808, doi: 10.1029/2009GL040000.

Huffman G.J., Bolvin D.T. \& Adler R.F. 2016. GPCP version 1.2 one-degree daily precipitation data set. Research Data Archive, National Center for Atmospheric Research, Computational and Information Systems Laboratory, Boulder, CO. doi: 10.5065/D6D50K46 26 May 2017.

Japan Meteorological Agency 2013. JRA-55: Japanese 55year reanalysis, daily 3-hourly and 6-hourly data. Research Data Archive, National Center for Atmospheric Research, Computational and Information Systems Laboratory, Boulder, CO. doi: 10.5065/ D6HH6H41 8 December 2016.

Jones R.W., Renfrew I.A., Orr A., Webber B.G.M., Holland D.M. \& Lazzara M.A. 2016. Evaluation of four global reanalysis products using in situ observations in the Amundsen sea embayment, Antarctica. Journal of Geophysical Research-Atmospheres 121, 6240-6257.

Kirchgäßner A. 2011. An analysis of precipitation data from the Antarctic base Faraday/Vernadsky. International Journal of Climatology 31, 404-414.

Kobayashi S., Ota Y., Harada Y., Ebita A., Moriya M., Onoda H., Onogi K., Kamahori H., Kobayashi C. \& Endo H. 2015. The JRA-55 reanalysis: general specifications and basic characteristics. Journal of the Meteorological Society of Japan Series II 93, 5-48.

Kochendorfer J., Rasmussen R., Wolff M., Baker B., Hall M. E., Meyers T., Landolt S., Jachcik A., Isaksen K., Braekkan R. \& Leeper R. 2017. The quantification and correction of wind-induced precipitation measurement errors. Hydrology and Earth System Sciences 21, 1973-1989.

Lachlan-Cope T., Ladkin R., Turner J. \& Davison P. 2001. Observations of cloud and precipitation particles on the Avery Plateau, Antarctic Peninsula. Antarctic Science 13, 339-348.

Li L. \& Pomeroy J.W. 1997. Probability of occurrence of blowing snow. Journal of Geophysical ResearchAtmospheres 102, 21955-22164.
Michaelides S., Levizzani V., Anagnostou E., Bauer P., Kasparis T. \& Lane J.E. 2009. Precipitation: measurement, remote sensing, climatology and modeling. Atmospheric Research 94, 512-533.

Miles G.M., Marshall G.J., McConnell J.R. \& Aristarain A.J. 2008. Recent accumulation variability and change on the Antarctic Peninsula from the ERA40 Reanalysis. International Journal of Climatology 28, 1409-1422.

Mo K.C., Shukla S., Lettenmaier D.P. \& Chen L.-C. 2012. Do climate forecast system (CFSv2) forecasts improve seasonal soil moisture prediction? Geophysical Research Letters 39, L23703, doi: 10.1029/2012GL053598.

Palerme C., Genthon C., Claud C., Kay J.E., Wood N.B. \& L'Ecuyer T. 2017. Evaluation of current and projected Antarctic precipitation in CMIP5 models. Climate Dynamics 48, 225-239.

Palerme C., Kay J.E., Genthon C., L’Ecuyer T., Wood N.B. \& Claud C. 2014. How much snow falls on the Antarctic ice sheet? The Cryosphere 8, 1577-1587.

Rasmussen R., Baker B., Kochendorfer J., Meyers T., Landolt S., Fischer A.P., Black J., Theriault J.M., Kucera P., Gochis D., Smith C., Nitu R., Hall M., Ikeda K. \& Gutmann E. 2012. How well are we measuring snow? The NOAA/FAA/NCAR winter precipitation test bed. Bulletin of the American Meteorological Society 93, 811-829.

Saha S., Moorthi S., Wu X.R., Wang J., Nadiga S., Tripp P., Behringer D., Hou Y.T., Chuang H.Y., Iredell M., Ek M., Meng J., Yang R.Q., Mendez M.P., van den Dool H., Zhang Q., Wang W.Q., Chen M.Y. \& Becker E. 2014. The NCEP climate forecast system version 2. Journal of Climate 27, 2185-2208.

Silva G.A.M., Dutra L.M.M., Da Rocha R.P., Ambrizzi T. \& Leiva E. 2014. Preliminary analysis on the global features of the NCEP CFSv2 seasonal hindcasts. Advances in Meteorology 2014, article no. 695067, doi: 10.1155/2014/ 695067.

Simmons A. 2006. ERA-Interim: new ECMWF reanalysis products from 1989 onwards. ECMWF Newsletter 110, 25-36.

Stephens G.L., Vane D.G., Boain R.J., Mace G.G., Sassen K., Wang Z.E., Illingworth A.J., O'Connor E.J., Rossow W. B., Durden S.L., Miller S.D., Austin R.T., Benedetti A. \& Mitrescu C., CloudSat Sci Team 2002. The Cloudsat mission and the A-train - a new dimension of spacebased observations of clouds and precipitation. Bulletin of the American Meteorological Society 83, 1771-1790.

Trammell J.H., Jiang X., Li L., Kao A., Zhang G.J., Chang E. K.M. \& Yung Y. 2016. Temporal and spatial variability of precipitation from observations and models. Journal of Climate 29, 2543-2555

Van Lipzig N.P.M., Turner J., Colwell S.R. \& van den Broeke M.R. 2004. The near-surface wind field over the Antarctic continent. International Journal of Climatology 24, 1973-1982.

Wang Y., Ding M., van Wessem J.M., Schlosser E., Altnau S., van den Broeke M.R., Lenaerts J.T.M., Thomas E.R., Isaksson E. \& Wang J. 2016. A comparison of Antarctic ice sheet surface mass balance from atmospheric climate models and in situ observations. Journal of Climate 29, 5317-5337.

Yang D.Q. 1999. An improved precipitation climatology for the Arctic Ocean. Geophysical Research Letters 26, 1625-1628.

Yuan X., Wood E.F., Luo L. \& Pan M. 2011. A first look at climate forecast system version 2 (CFSv2) for hydrological seasonal prediction. Geophysical Research Letters 38, L13402, doi: 10.1029/2011GL047792. 